\title{
HIV-1 binding and neutralizing antibodies of injecting drug users
}

E.P. Ouverney ${ }^{1}$, S.L.M. Teixeira ${ }^{1}$, C. Silva-de-Jesus ${ }^{1}$, M.A. Hacker ${ }^{2}$, M.G. Morgado ${ }^{1}$, F.I. Bastos ${ }^{2}$ and V. Bongertz ${ }^{1}$
${ }^{1}$ Laboratório de AIDS e Imunologia Molecular, Departamento de Imunologia, ${ }^{2}$ Centro de Informação Científica e Tecnológica, Instituto Oswaldo Cruz, Fundação Oswaldo Cruz, Rio de Janeiro, RJ, Brasil

\section{Correspondence}

E.P. Ouverney

Laboratório de AIDS e

Imunologia Molecular

Departamento de Imunologia

Instituto Oswaldo Cruz, FIOCRUZ

Av. Brasil, 4365

21045-900 Rio de Janeiro, RJ

Brasil

Fax: +55-21-2290-4110

E-mail: elainepriscilla@yahoo.com

Research supported by $\mathrm{CNPq}$ and FAPERJ.

Received July 30, 2004

Accepted April 1, 2005

\section{Abstract}

Previous studies have demonstrated a stronger seroreactivity against some synthetic peptides responsible for inducing neutralizing antibodies in injecting drug users (IDU) compared to that of individuals sexually infected with HIV-1 (S), but the effectiveness in terms of the neutralizing ability of these antibodies has not been evaluated. Our objective was to study the humoral immune response of IDU by determining the specificity of their antibodies and the presence of neutralizing antibodies. The neutralization capacity against the HIV1 isolate MN (genotype B), the primary HIV-1 isolate 95BRRJ021 (genotype F), and the seroreactivity with peptides known to induce neutralizing antibodies, from the V2 and V3 loops of different HIV-1 subtypes, were analyzed. Seroreactivity indicates that IDU plasma are more likely to recognize a broader range of peptides than S plasma, with significantly higher titers, especially of V3 peptides. Similar neutralization frequencies of the $\mathrm{MN}$ isolate were observed in plasma of the IDU (16/47) and S (20/60) groups in the 1:10 dilution. The neutralization of the 95BRRJ021 isolate was more frequently observed for plasma from the S group (15/23) than from the IDU group (15/47, $\mathrm{P}=0.0108)$. No correlation between neutralization and seroreactivity with the peptides tested was observed. These results suggest that an important factor responsible for the extensive and broad humoral immune response observed in IDU is their infection route. There was very little difference in neutralizing antibody response between the IDU and S groups despite their differences in seroreactivity and health status.

\section{Introduction}

The use of injection drugs is an important route of HIV-1 transmission, currently representing one of the major modes of infection in North Africa, the Middle East, Asia, Latin America, North America, and Europe
Key words

- HIV-1

- Injecting drug users

- Antibodies

- Neutralization
(1). According to the HIV/AIDS epidemic report published by UNAIDS after the XIV International AIDS Conference (2002), this transmission mode is especially important in countries like Austria (27.0\%), Italy (33.6\%), Thailand (39.6\%), and Brazil, where, according to more recent data, $20.6 \%$ of the 
AIDS cases were reported to be in injecting drug users (IDU) (2).

There is evidence indicating that HIV-1infected IDU progress more slowly to AIDS than individuals infected by the sexual route, independent of age, sex, time of seroconversion, or antiretroviral therapy (3). One of the hypotheses proposed is that the continuous activation of the immune response in IDU, prior to infection, is responsible for inducing a fast and high immune response (3). There should also be differences in HIV-1 selection in the different exposure groups: while in sexually transmitted HIV-1 selection may occur due to passage through different tissues, in IDU no such pre-selection could occur since the virus is directly introduced into the bloodstream. Therefore, for IDU the selection should be restricted by the susceptibility of blood mononuclear cells and by the different variants of the HIV-1 that are introduced directly into the blood.

Previous studies of HIV-1-positive Brazilian sera (4) showed an especially frequent reactivity against synthetic viral envelope peptides in IDU plasma compared to plasma from individuals belonging to other HIV-1 exposure categories (pregnant women, men that have sex with men, and sexually infected recent seroconverters). This observation indicates that the transmission mode of HIV-1 seems to be more predictive of the extent and titer of seroreactivity than the progress of the infection (indicated by the number of circulating CD4 T cells) or gender (5). The recognition of peptides important for an effective immune response (6) might be correlated to the fact that IDU with AIDS have a survival rate similar to the one observed in non-IDU, despite their numerous co-infections associated or not with AIDS (7).

A broader immune response has been correlated with a more complete virus control rather than a more specific response $(8,9)$, and this could be an explanation for the equivalent survival of seropositive IDU and of individuals from sexual exposure categories. The objective of the present study was to analyze the amplitude and effectiveness of the humoral immune response of HIV-1-infected IDU.

\section{Material and Methods}

\section{Plasma samples}

Plasma samples from 48 HIV-1-infected IDU were used. The IDU group was composed of individuals with the following characteristics: $18.8 \%$ (9/48) females, and $78.3 \%$ infected with HIV-1 B and $21.7 \%$ with the HIV-1 F env genotype as determined by the heteroduplex mobility assay (10). Thirty percent (13/43) of the plasma samples were collected when the individuals had less than $15.0 \% \mathrm{CD} 4 \mathrm{~T}$ cells. Absolute numbers of CD4 lymphocytes at sample collection were not available for the IDU samples. Thirtyeight percent of the IDU (15/40) had a viral load above 30,000 RNA copies/ml at sample collection. Individuals were classified as asymptomatic or symptomatic, and the presence of co-infections reported at sample collection was recorded by the responsible medical doctor. Only 6 of the 48 HIV-infected IDU were under anti-retroviral treatment at the time of sample collection.

A group of purportedly sexually infected individuals (S) was used for comparative analysis. This group consisted of 60 individuals, 22 of whom were females (33.7\%), and $22.2 \%(10 / 45)$ had less than $15.0 \%$ CD4 $\mathrm{T}$ cells. Ninety-one percent of the individuals were infected with the HIV-1 B genotype and $9.0 \%$ with the HIV-1 F genotype $(11,12)$. As usual, the laboratory jargon "B plasma" or "F plasma" was used to indicate "plasma samples from individuals infected with B genotype HIV-1" or "samples from individuals infected with F genotype HIV-1", to avoid the high number of repetitions. No information on viral load was available at sample collection. Seven of the 60 partici- 
pants were under anti-retroviral treatment at sample collection.

A group of plasma samples from $14 \mathrm{HIV}$ 1 seronegative IDU was used as negative control.

The study was approved by the FIOCRUZ Ethics Research Committee before sample collection and written informed consent was obtained from all participants.

\section{Virus isolates}

The HIV-1 MN isolate (genotype B, X4, $T$ cell line adapted (TCLA) virus) and the Brazilian primary isolate 95BRRJ021 (13) (isolated in 1995 and stored at $-80^{\circ} \mathrm{C}$ until use, genotype $\mathrm{F}$, as recently confirmed, R5, non-syncytium inducer (14). No more than 5 passages in peripheral blood mononuclear cells) were used.

\section{Seroreactivity test}

Several custom-made biotinylated synthetic peptides (Chiron Mimotopes, San Diego, CA, USA) corresponding to "neutralizing epitopes" of the HIV-1 envelope were used in an ELISA: a) corresponding to the consensus V3 loop peptides of HIV-1 B (V3B = TRKSIHIGPGRAFY), Brazilian variant $\mathrm{Bbr}$ of the $\mathrm{B}$ genotype $(\mathrm{V} 3 \mathrm{Bbr}=\mathrm{NT}$ RKSIHMGWGRAFY), C (V3C = KSIR IGPGQTFYAT), D (V3D = RQRTHIGP GQALYTT), E (V3E = TSITIGPGQVF YRT), F (V3F = RKSIHLGPGQFYTT), and a Brazilian $\mathrm{F}$ subtype $(\mathrm{V} 3 \mathrm{Fbr}=$ NTRKSIPLGPGRAFY); b) corresponding to gp120 V2 loops of HIV-1 subtype B isolate $\mathrm{MN}(\mathrm{V} 2 \mathrm{MN}=$ IRDKMQKEUALLY $\mathrm{KL}$ ) and to a Brazilian Bbr primary isolate (V2BR = VKDKEKKEYALFYNL); c) peptides corresponding to conserved neutralizing epitopes in HIV-1 MN gp41, amino acids 735-752 (735 = DRPEGIEEEGEKDRDS $)$ and amino acids 669-674 (eld = ELDKWA), as well as the immunodominant epitope in gp41 of the HIV-1 isolate MN (ID = CS
GKLICT). Heat-inactivated plasma samples were diluted sequentially (1:100 in a first step, followed by dilutions using factors 2,5 or 10 of positive plasma) and incubated in duplicate with peptides bound to avidincoated plates as described before (15), including an $8 \mathrm{M}$ urea wash, to reduce nonspecific binding.

\section{Neutralization assay}

All plasma samples from the IDU group were tested for their ability to neutralize the HIV-1 MN and the 95BRRJ021 isolates. From the $\mathrm{S}$ group, all plasma samples were tested against the HIV-1 MN isolate, and 23 samples were tested against the 95BRRJ021 isolate. At least 3-fold plasma dilutions, using 1:10 as the first step, were used.

Neutralization of the HIV-1 MN isolate replication was tested using the CEM cell line $\left(10^{4}\right.$ cells/well $)$ and neutralization of the primary isolate was tested using phytohemagglutinin-pre-activated normal human peripheral blood mononuclear cells $\left(10^{5}\right.$ cells/ well) and a multiplicity of infection of $0.001-$ 0.005 (10-50 infective units per well), according to WHO-UNAIDS Guidelines (16). Quantification of the HIV-1 p24 antigen (HIV-1 p24 ELISA - Coulter Corporation, Miami, FL, USA) was carried out on the seventh day of cell culture. Positive control wells containing virus and cells (without human serum), assay wells containing virus, cells and serially diluted plasma samples, negative control wells containing virus, cells and normal human serum, background values (wells containing only cells), and wells used for determining the $50 \%$ tissue culture infective dose of the virus isolate were prepared simultaneously (17). Approximate plasma concentrations needed for neutralizing 90 and $100 \%$ of the viral input (90 or $100 \%$ neutralization levels, respectively) were derived from linear regression curves (MicroCal Origin Software Inc., Northampton, MA, USA) or directly from the neutral- 
ization curve, when the plot of the values gave a straight line.

\section{Statistical analysis}

Data were analyzed statistically with the Instat software (Graph Instat tm, 1990-1994, San Diego, CA, USA) using the unpaired Student $t$-test for comparison of age, CD4 T cell counts and viral load, and contingency table (chi-square or exact Fisher test) for categorical variables. Linear regression was plotted using the MicroCal Origin software.

\section{Results}

\section{Clinical parameters, gender and age distribution}

The IDU and S groups compared in this study presented some important differences:

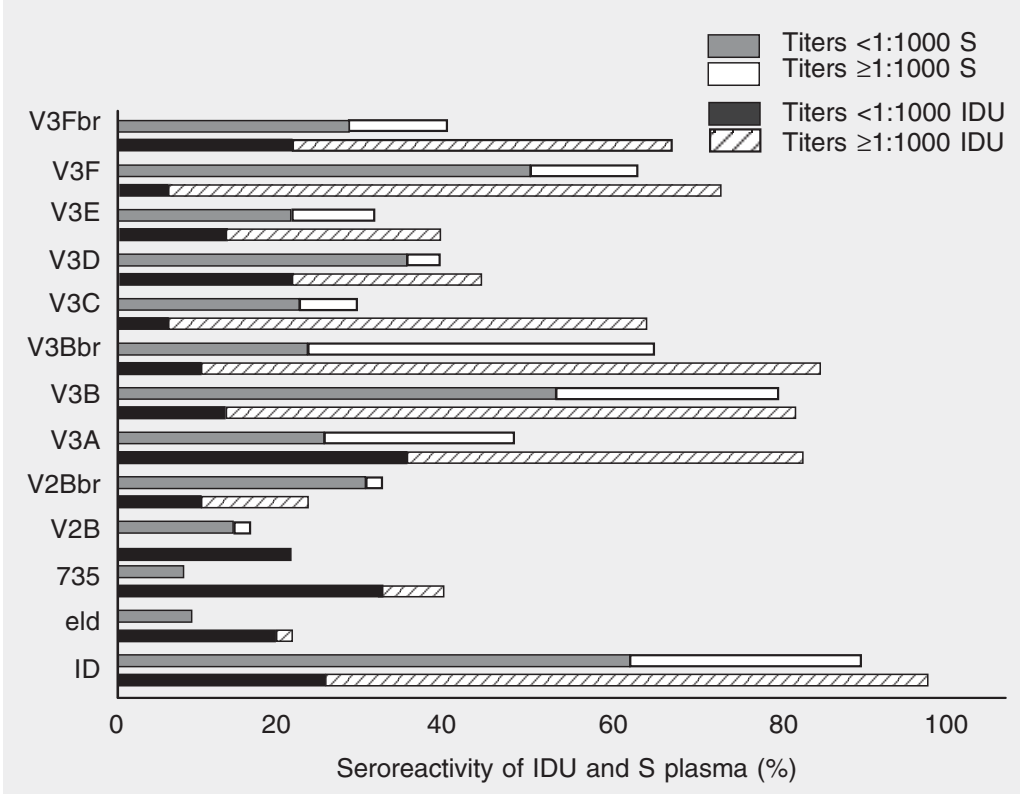

Figure 1. Seroreactivity of plasma from injecting drug users (IDU) and sexually infected individuals (S) against synthetic peptides. Data are reported as percent of individuals with titers of seroreactivity in plasma corresponding to the inset at the top of the figure. Plasma was tested against synthetic peptides corresponding to epitopes responsible for the induction of neutralizing antibodies from the V3 and V2 loop of HIV-1 gp120, from the genotypes/ variants A, B, Bbr, C, D, E, F, and Brazilian Fbr, and against the HIV-1 MN gp41 amino acids 735-752 (735) and 669-674 (eld), as well as the immunodominant epitope in gp41 of the same isolate $(I D=$ CSGKLICT $)$. a) gender distribution, with the $\mathrm{S}$ group containing a higher proportion of females (22/ 60 versus $9 / 48, \mathrm{P}=0.05)$, b) percentage of $\mathrm{CD} 4 \mathrm{~T}$ lymphocytes at sample collection, which was much higher for the $S$ group (26.0 $\pm 10.1)$ than the IDU group $(20.5 \pm 9.4, \mathrm{P}=$ 0.0045 ), and c) lower frequency of former clinical symptomatology reported by the $\mathrm{S}$ group volunteers $(16 \%)$ than the IDU group individuals $(98 \%, \mathrm{P}<0.0001)$.

There was no significant difference in gender (39/48 males versus 14/14, respectively) or age between the HIV-infected and the seronegative IDU groups. As expected, much higher percentages of CD4 T lymphocytes were detected in non-infected individuals $(\mathrm{P}<0.0001)$.

\section{Seroreactivity}

Reactivity against some of the peptides used (V3A, $\mathrm{P}=0.0002$; V3Bbr, $\mathrm{P}=0.0261$; V3C, $\mathrm{P}=0.0002$; V3Fbr, $\mathrm{P}<0.0001$ ) (Figure 1) was more likely to be found in IDU than in S plasma. The antibody titers against most of the peptides were much higher in IDU than in S plasma samples with a clear difference being observed when the reactivity of plasma diluted a thousand times or more was compared: ID ( $\mathrm{P}<0.0001), \mathrm{V} 2 \mathrm{~B}$, V2Bbr, V3A $(\mathrm{P}=0.008)$, V3B $(\mathrm{P}<0.0001)$, V3Bbr $(\mathrm{P}=0.0008), \mathrm{V} 3 \mathrm{C}(\mathrm{P}=0.0001), \mathrm{V} 3 \mathrm{D}$ $(\mathrm{P}=0.0055), \mathrm{V} 3 \mathrm{E}(\mathrm{P}=0.047), \mathrm{V} 3 \mathrm{~F}(\mathrm{P}<$ $0.0001)$, and V3Fbr $(\mathrm{P}=0.0001$; Figure 1$)$.

Seroreactivity was not affected by gender, CD4 T cell percentages, or viral load at blood collection (data not shown).

\section{Neutralization}

Similar neutralization frequencies of the reference isolate HIV-1 MN were observed in the first plasma dilution steps: a total of $34 \%$ (16/47) IDU and of 33\% (20/60) S plasma samples were able to neutralize the total MN HIV-1 input (100\% level). However, $100 \%$ neutralization of the HIV-1 iso- 
late 95BRRJ021 was much more frequently observed for plasma from the $\mathrm{S}$ group (15/ $23,65 \%)$ than for plasma from the IDU group $(15 / 47,32 \% ; \mathrm{P}=0.0108)$ at $1: 10$ plasma dilution. The high susceptibility of the primary $\mathrm{F}$ genotype isolate 95BRRJ021 has been previously described, and motivated the choice of this isolate in the present study (13). This high susceptibility of the F genotype primary isolate agreed with the higher neutralizing ability of $\mathrm{F}$ plasma, both for plasma from the IDU group $(8 / 35 \mathrm{~B}$ plasma vs $6 / 10 \mathrm{~F}$ plasma neutralized the 95BRRJ021 HIV-1 isolate, $\mathrm{P}=0.0488$ ) and the total $\mathrm{F}$ versus $\mathrm{B}$ genotype plasmas used for neutralization of this isolate (17/52 B vs $11 / 15 \mathrm{~F}, \mathrm{P}=0.0073)$. The plasma samples from individuals infected by $\mathrm{F}$ genotype virus were less effective against the HIV-1 $\mathrm{MN}$ isolate since only $1 / 5$ plasma from the $S$ group and 5/9 from the IDU group were able to neutralize this isolate.

None of the 14 plasma samples from seronegative IDU neutralized the HIV-1 isolates.

When the neutralization of the two HIV1 isolates by IDU plasma was compared, a slightly higher frequency of neutralization (at the $100 \%$ level of neutralization) of the $\mathrm{MN}$ isolate was observed, but at the $90 \%$ neutralization level a slightly more frequent neutralization of the 95BRRJ021 isolate was observed (Figure 2).

When the neutralization of the two isolates by plasma from the $\mathrm{S}$ group was compared a more likely neutralization of the HIV-1 95BRRJ021 isolate was observed, mainly due to the higher neutralization observed with plasma from individuals infected by $\mathrm{F}$ genotype virus. Comparison of the neutralization of the HIV-1 MN and 95BRRJ021 HIV-1 isolates is shown in Figure 2.

Gender, T CD4 cell percentage or viral load of the IDU plasma donors did not affect the neutralizing ability of the tested plasma (data not shown).

\section{Correlation between neutralization and seroreactivity}

There was no correlation between neutralizing capacity and seroreactivity against the synthetic peptides used in our assays, chosen because they are known to be able to induce neutralizing antibodies. Plasma with a high neutralizing ability could have any level of seroreactivity, and plasma with a high seroreactivity could have zero to $100 \%$ neutralization ability.

\section{Discussion}

When the IDU and S groups were compared, significantly higher reactivity against some HIV-1 peptides was observed for the IDU group. Also, the titers of seroreactivity of IDU plasma were much higher than those of S plasma against the peptides from the V2 and V3 loop, and the immunodominant peptide. These data reaffirm the more amplified immune response in IDU, as suggested before, and agree with the data from another study (18) which found that HIV-1-sero-

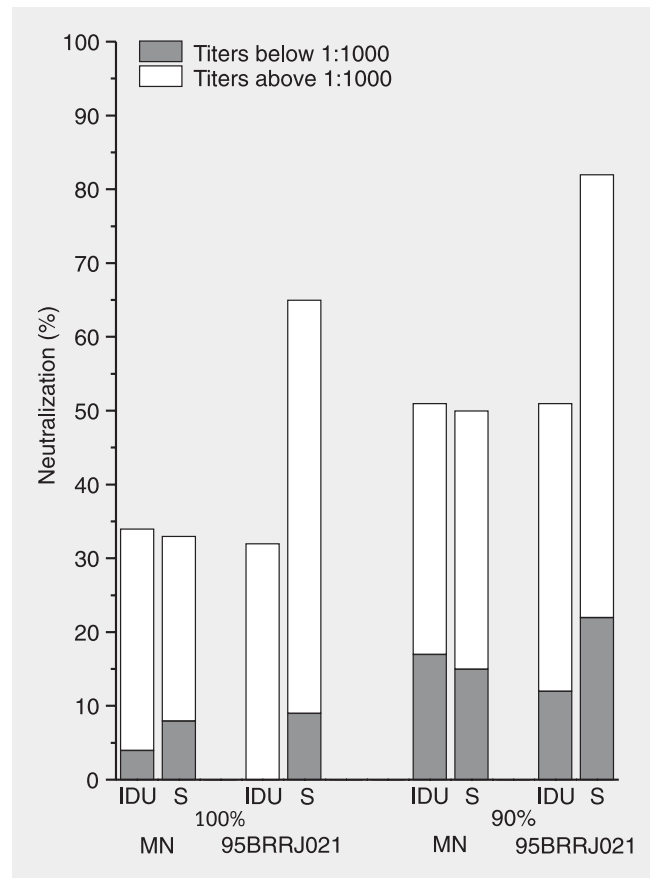

Figure 2. Neutralization of the HIV-1 isolates 95BRRJ021 and MN by plasma of injecting drug users (IDU) and sexually infected patients (S), at 90 and $100 \%$. 
positive IDU have a stronger humoral immune response against viral matrix antigens when compared to seropositive homosexuals. In the present study, the majority of the men from the $S$ group (29/38) also belonged to this exposure category.

Although the literature shows a better immune response in healthier individuals (19-21), no correlation was observed between seroreactivity or neutralization and clinical status in the individuals studied. The frequent and potent viral neutralization, especially of the 95BRRJ021 isolate, by $\mathrm{S}$ plasma could be a consequence of their good health. This inference is also applicable to the plasma from IDU, with most individuals having a compromised health status, and with low percentages of plasma neutralizing the 95BRRJ021 isolate. One of the observations of this study was that plasma samples from individuals infected by $\mathrm{F}$ genotype virus are more likely to neutralize the F genotype primary isolate, showing strong intraclade neutralization, as reported for other genotypes $(22,23)$, but also a marked neutralization of $\mathrm{B}$ clade virus, indicating that clade F HIV-1 induces a very broad and strong humoral immune response. These data indicate that an HIV-1 F genotype vaccine would be preferable to a genotype B virusbased vaccine, but more extensive studies are necessary to confirm this indication.

Within the IDU group, this absence of correlation could be explained by the poor health status of the individuals, who frequently had different co-infections and low numbers of CD4 T cells. This could result from the differences in exposure to the virus, since in IDU the viral selection should be restricted to the susceptibility of mononuclear blood cells (8), possibly reinforced by the use of injected drugs, most importantly cocaine (24), as secondary immune stimulators $(18,25)$. It is possible, therefore, that the route of transmission of the virus is at least as important in the induction of the humoral immune response as the health status of the individual, as demonstrated before (4).

It should be noted that linear regression might not be the ideal way to evaluate HIV neutralization since there is non-linearity in neutralization curves, and linear regression calculations are quite often lower than the experimentally determined values. However, linear regression is a method that allows the calculation of the exact titer desired, even if it underestimates the neutralization actually observed.

When the neutralization of the MN and 95BRRJ021 isolates by IDU plasma was compared, it was possible to detect a slightly higher neutralization frequency at $100 \% \mathrm{lev}-$ els of the MN isolate, but neutralization at lower levels was a little more frequent for the 95BRRJ021 isolate. However, the neutralization pattern of the two isolates was closely similar.

It is important to call attention to the significance of the $100 \%$ neutralization level, when all virion input is neutralized. The importance of in vitro higher neutralization titers has been shown before $(26,27)$, demonstrating that there is a strong correlation between higher neutralization titers and protection.

The neutralization of the 95BRRJ021 isolate was more frequent for the sexually infected individuals $(P=0.0013)$. The very high neutralization susceptibility of this isolate was unexpected because primary isolates are normally more resistant to neutralization than TCLA viruses (28-30). However, the high susceptibility of the 95BRRJ021 primary isolate confirms previous observations of high susceptibility of Brazilian F genotype HIV-1 (3). We may speculate that this primary isolate presents only limited glycan shielding (31) or less cryptic neutralization epitopes (32) than usually observed in HIV-1 primary isolate.

No correlation between the neutralization ability of plasma and seroreactivity against the synthetic peptides was observed in this study, although the peptides were 
chosen because of their known capacity to induce neutralizing antibodies. These results agree with data from other Brazilian studies $(3,14)$, as well as with studies from other countries (33-35); however, they disagree with other studies in which a correlation was observed between neutralization and seroreactivity against the peptide ELDKWA (36), peptides from gp120 and gp41 (37), and peptides from the V3 loop $(38,39)$.

These results indicate that, although IDU have a broader $\mathrm{V} 3$ peptide recognition, which might be important since V3 is known as the "principal neutralizing determinant" of TCLA HIV-1 (40), their effective (neutralizing) immune response is not as extensive as that observed for sexually infected individuals. However, is it higher than would be expected for individuals who report frequent co-infections. It is possible that the chronically activated immune system of IDU does allow a fast and extensive response.

\section{Acknowledgments}

We are grateful to HEMORIO (Instituto Estadual de Hematologia Artur de Siqueira Cavalcanti, Rio de Janeiro, RJ, Brazil) for the buffy coats received (especially to Terezinha Miranda Ferreira), to Saada L.C. Fernandez for the confirmation of the 95BRRJ021 genotype (July 2003), to the Brazilian Network of Isolation and Characterization of HIV, and to Dr. B. Galvão Castro, LASP/FIOCRUZ, for the primary viral isolate used in this study.

\section{References}

1. UNAIDS. Frequently asked questions. $<<h t t p: / / w w w . u n a i d s . o r g /$ hivaidsinfo/faq/variability.html>>. Accessed April 2003.

2. Brazilian Ministry of Health. <http://www.aids.gov.br>. Accessed September 2002.

3. Pehrson P, Lindback S, Lidman C, Gaines H \& Giesecke J (1997). Longer survival after HIV infection for injecting drug users than for homosexual men: implications for immunology. AIDS, 11: 10071012.

4. Bongertz V, Guimaraes ML, Soares-da-Costa MF et al. (1999). AntiHIV-1 seroreactivity and HIV transmission route. Journal of Clinical Virology, 12: 27-36.

5. Bongertz V, Costa Cl, Guimaraes ML et al. (1998). HIV specific humoral immune response in Rio de Janeiro, Brazil. Memórias do Instituto Oswaldo Cruz, 93: 391-398.

6. McKeating JA (1996). Biological consequences of HIV-1 envelope polymorphism: does variation matter? Journal of General Virology, 77: 2905-2919.

7. Manoff SB, Vlahov D, Herskowitz A, Solomon L, Munoz A, Cohn S, Willoughby SB \& Nelson KE (1996). Human immunodeficiency virus infection and infective endocarditis among injecting drug users. Epidemiology, 7: 566-570.

8. Fenyö EM, Albert J \& McKeating J (1996). The role of the humoral immune response in HIV infection. AIDS, 10 (Suppl A): S97-S106.

9. Ngo-Giang-Huong N, Candotti D, Goubar A et al. (2001). HIV type 1specific IgG2 antibodies: markers of helper $T$ cell type 1 response and prognostic marker of long-term nonprogression. AIDS Research and Human Retroviruses, 17: 1435-1446.

10. Delwart EL, Shpaer EG, Louwagie J, McCutchan FE, Grez M, Rubsamen-Waigmann H \& Mullins JI (1993). Genetic relationships determined by a DNA heteroduplex mobility assay: analysis of HIV1 env genes. Science, 262: 1257-1261.
11. Morgado MG, Guimaraes ML, Gripp CB et al. (1998). Molecular epidemiology of HIV-1 in Brazil: high prevalence of HIV-1 subtype B and identification of an HIV-1 subtype D infection in the city of Rio de Janeiro, Brazil. Evandro Chagas Hospital AIDS Clinical Research Group. Journal of Acquired Immune Deficiency Syndromes and Human Retrovirology, 18: 488-494.

12. Bongertz V, Ouverney EP, Teixeira SL, Silva-de-Jesus C, Hacker MA, Morgado MG \& Bastos FI (2003). Higher anti-HIV-1 antibody titers in injection drug users compared to sexually infected individuals. Memórias do Instituto Oswaldo Cruz, 98: 209-212.

13. Bongertz V, Bou-Habib DC, Brigido LF et al. (2000). HIV-1 diversity in Brazil: genetic, biologic, and immunologic characterization of HIV1 strains in three potential HIV vaccine evaluation sites. Journal of Acquired Immune Deficiency Syndrome, 23: 184-193.

14. Ferraro GA, Mello MA, Sutmoller F, Van Weyenbergh J, Shindo N, Galvao-Castro B, Bou-Habib DC \& Brazilian Network for HIV Isolation and Characterization (2001). Biological characterization and chemokine receptor usage of HIV type 1 isolates prevalent in Brazil. AIDS Research and Human Retroviruses, 17: 1241-1247.

15. Lukashov VV \& Goudsmit J (1997). Founder virus population related to route of virus transmission: a determinant of intrahost HIV type 1 evolution? Journal of Virology, 71: 2023-2030.

16. WHO-UNAIDS HIV-1 Vaccine Initiative, Initiative for Vaccine Research, Health Technology ang Pharmaceutical, World Health Organization (2002). WHO-UNAIDS Guidelines for Standard HIV Isolation and Characterization Procedures. 2nd edn. World Health Organization, Geneve, Switzerland.

17. Bongertz V, Costa Cl, Veloso VG, Grinsztejn B, Filho EC, Calvet G \& Pilotto JH (2001). Vertical HIV-1 transmission: importance of neutralizing antibody titer and specificity. Scandinavian Journal of Immunology, 53: 1-9. 
18. Jiang JD \& Bekesi GJ (2001). Antibody responses to HIV-1 antigens are higher in $\mathrm{HIV}-1(+)$ intravenous drug users than in HIV-1(+) homosexuals. Biomedicine and Pharmacotherapy, 55: 313-315.

19. Robert-Guroff M, Oleske JM, Connor EM, Epstein LG, Minnefor AB \& Gallo RC (1987). Relationship between HTLV-III neutralizing antibody and clinical status of pediatric acquired immunodeficiency syndrome (AIDS) and AIDS-related complex cases. Pediatric Research, 21: 547-550.

20. Page M, Vella C, Corcoran T, Dilger P, Ling C, Heath A \& Thorpe R (1992). Restriction of serum antibody reactivity to the V3 neutralizing domain of HIV gp120 with progression to AIDS. AIDS, 6: 441446.

21. Jolly PE \& Weiss HL (2000). Neutralization and enhancement of HIV-1 infection by sera from HIV-1 infected individuals who progress to disease at different rates. Virology, 273: 52-59.

22. Mascola JR, Louder MK, Surman SR et al. (1996). Human immunodeficiency virus type 1 neutralizing antibody serotyping using serum pools and an infectivity reduction assay. AIDS Research and $\mathrm{Hu}$ man Retroviruses, 12: 1319-1328.

23. Zolla-Pazner S (2004). Identifying epitopes of HIV-1 that induce protective antibodies. Nature Reviews. Immunology, 4: 199-210.

24. Lima ES, Friedman SR, Bastos FI, Telles PR, Friedmann P, Ward TP \& des Jarlais DC (1994). Risk factors for HIV-1 seroprevalence among drug injectors in the cocaine-using environment of Rio de Janeiro. Addiction, 89: 689-698.

25. Stanulis ED, Matulka RA, Jordan SD, Rosecrans JA \& Holsapple MP (1997). Role of corticosterone in the enhancement of the antibody response after acute cocaine administration. Journal of Pharmacology and Experimental Therapeutics, 280: 284-291.

26. Mascola JR (2002). Passive transfer studies to elucidate the role of antibody-mediated protection against HIV-1. Vaccine, 20: 19221925.

27. Moore JP \& Burton DR (1999). HIV-1 neutralizing antibodies: how full is the bottle? Nature Medicine, 5: 142-144.

28. Cohen J (1993). Jitters jeopardize AIDS vaccine trials. Science, 262: $980-981$.

29. Matthews TJ (1994). Dilemma of neutralization resistance of HIV-1 field isolates and vaccine development. AIDS Research and Human Retroviruses, 10: 631-632.

30. Moore JP \& Ho DD (1995). HIV-1 neutralization: the consequences of viral adaptation to growth on transformed T cells. AIDS, 9 (Suppl 1): S117-S136.
31. Wei X, Decker JM, Wang S et al. (2003). Antibody neutralization and escape by HIV-1. Nature, 422: 307-312.

32. Bou-Habib DC, Roderiquez G, Oravecz T, Berman PW, Lusso P \& Norcross MA (1994). Cryptic nature of envelope V3 region epitopes protects primary monocytotropic human immunodeficiency virus type 1 from antibody neutralization. Journal of Virology, 68: 60066013.

33. Warren RQ, Anderson SA, Nkya WM, Shao JF, Hendrix CW, Melcher GP, Redfield RR \& Kennedy RC (1992). Examination of sera from human immunodeficiency virus type 1 (HIV-1)-infected individuals for antibodies reactive with peptides corresponding to the principal neutralizing determinant of HIV-1 gp120 and for in vitro neutralizing activity. Journal of Virology, 66: 5210-5215.

34. Ayyavoo V, Ugen KE, Fernandes LS, Goedert JJ, Rubinstein A, Williams WV \& Weiner DB (1996). Analysis of genetic heterogeneity, antigenicity, and biological characteristics of HIV-1 in a maternal transmitter and nontransmitter patient pair. DNA and Cell Biology, 15: $571-578$.

35. Nyambi PN, Lewi P, Peeters M et al. (1997). Study of the dynamics of neutralization escape mutants in a chimpanzee naturally infected with the simian immunodeficiency virus SIVcpz-ant. Journal of Virology, 71: 2320-2330.

36. Calarota S, Jansson M, Levi M, Broliden K, Libonatti O, Wigzell H \& Wahren B (1996). Immunodominant glycoprotein 41 epitope identified by seroreactivity in HIV type 1-infected individuals. AIDS Research and Human Retroviruses, 12: 705-713.

37. Broliden PA, von Gegerfelt A, Clapham P, Rosen J, Fenyo EM, Wahren B \& Broliden K (1992). Identification of human neutralization-inducing regions of the human immunodeficiency virus type 1 envelope glycoproteins. Proceedings of the National Academy of Sciences, USA, 89: 461-465.

38. Bongertz V, Morgado MG, Galvão-Castro B, Wigzell H \& Hendry RM (1994). Correlation between anti-V3 peptide and neutralizing antibodies in plasma from HIV-1 infected individuals resident in Brazil. Memórias do Instituto Oswaldo Cruz, 89: 113-114.

39. Broliden PA, Makitalo B, Akerblom L, Rosen J, Broliden K, Utter G, Jondal M, Norrby E \& Wahren B (1991). Identification of amino acids in the V3 region of gp120 critical for virus neutralization by human HIV-1-specific antibodies. Immunology, 73: 371-376.

40. Ratner L, Haseltine W, Patarca R et al. (1985). Complete nucleotide sequence of the AIDS virus, HTLV-III. Nature, 313: 277-284. 